Revistade
Economíd
Contemporâned

\title{
UM NACIONALISMO DEMOCRÁTICO PARA O SÉCULO XXI
}

\author{
Marcus Ianoni ${ }^{a}$ \\ Felipe Maruf Quintas ${ }^{b}$ \\ åDepartamento de Ciência Política da Universidade Federal Fluminense (UFF).

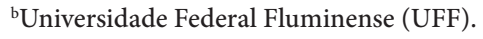 \\ BRESSER-PEREIRA, L. C. A construção política do Brasil: sociedade, economia e Estado desde a \\ Independência. São Paulo: Editora 34, 2014.
}

A problematização das condições históricas em que se dá a busca da afirmação de uma identidade nacional singular e da (re)construção nacional conforme as particularidades existentes é uma questão premente no pensamento social brasileiro. Compartilhamos da avaliação de que as obras dos intelectuais brasileiros que pensaram a Nação contêm a formulação de um pensamento, e não de uma teoria, um pensamento sobre a história, o povo e as possibilidades nacionais. Essa distinção está estabelecida por Christian Lynch (2013) e refletiria a internalização, pelos intelectuais brasileiros, da dependência do Brasil, país periférico, em relação ao centro europeu e estadunidense. A teoria seria própria do centro, sistematicamente ordenada em cadeias de abstração generalizantes, ao passo que o pensamento, produzido na periferia, seria mais concreto, fragmentário, preocupado com questões mais específicas.

Ao apresentar sua obra A construção política do Brasil, Luiz Carlos Bresser-Pereira inclui o conjunto de reflexões sobre o país nela contidas como pensamento ou grande interpretação histórica. Mas ele não pode ser acusado de falta de ambição. O pensamento contido nesse livro preserva uma das características mais gerais do pensamento social brasileiro: um impulso fundamental de transformação, de avanço e de melhoramento, sempre fundamentado em vasta pesquisa sobre a formação do país e a singularidade que o marca, elemento que qualquer projeto deverá levar plenamente em conta, se quiser ser bem-sucedido.

Correspondência para: Marcus Ianoni.

Contato: marcus.ianoni@gmail.com. 
No âmago da imensa diversidade que caracteriza o pensamento social brasileiro, certas regularidades relativas à matriz intelectual de cada autor podem ser estabelecidas. Há o liberalismo, presente em Joaquim Nabuco, Sérgio Buarque de Holanda e Raymundo Faoro. Em linhas gerais, para os liberais, a formação do Brasil não se deu no sentido dos regimes constitucionais e pluralistas do Atlântico Norte, mas se formou sob a herança ibérica (Buarque de Holanda e Faoro), personalista e patrimonialista. Trata-se de sociedade alheia à cidadania e aos direitos civis, sendo desigual o status dos indivíduos. Ademais, a economia e a ação empresarial privada são tuteladas e tolhidas por um Estado patrimonial e protetor de interesses particulares que capturam o poder público.

Há os marxistas, como Caio Prado Júnior e Florestan Fernandes, para os quais a formação do Brasil, desde a Colônia, teria se dado no sentido da integração subordinada, periférica e dependente ao capitalismo enquanto sistema econômico mundial. Essa inserção teria condicionado estruturalmente o rumo seguido após a Independência, que não se deu no sentido do desenvolvimento nacional autônomo, mas do capitalismo dependente e subdesenvolvido. Não haveria, portanto, alternativa ao subdesenvolvimento sem romper com o capitalismo e realizar o socialismo por meio de uma revolução popular.

Já os nacionalistas, representados por Oliveira Vianna, pelo ISEB e Celso Furtado, colocam como questão principal a promoção da Nação e dos interesses nacionais por meio de um processo de reconstrução da política. A política deve ser dirigida pelas forças sociais promotoras da construção da nação autônoma e soberana, que tenha um centro dinâmico próprio, independente de outros países. É nessa corrente nacionalista que Bresser-Pereira se situa. Mas ele também incorpora o liberalismo em sua análise, sobretudo a defesa de um Estado livre do patrimonialismo e zeloso pelas liberdades individuais, consoante o Estado de Direito, mas também a abordagem participativa da liberal-democracia, ao valorizar a participação popular autônoma. Também incorpora elementos marxistas, de compreensão totalizante do Brasil como uma nação capitalista, dividida em classes e formada sob a dependência, primeiramente, da metrópole portuguesa e, posteriormente, dos centros capitalistas. Nessa apreensão dialética, economia, política e sociedade se inter-relacionam historicamente. Mas Bresser-Pereira rejeita a dimensão econômica do liberalismo, que defende a autorregulação do mercado como o principal mecanismo de organização da produção e da distribuição. Ele vislumbra o desenvolvimento nacional e a libertação da condição de dependência como meta principal e o Estado como ator estratégico das transformações. Ao contrário dos marxistas, não considera o socialismo a única alternativa à dependência, embora não o descarte. $\mathrm{O}$ horizonte político de Bresser-Pereira situa-se no terreno do reformismo democrático-burguês, sendo o desenvolvimento capitalista sua preocupação essencial.

A construção política do Brasil faz uma periodização da história do Brasil, compreendendo a formação nacional brasileira por meio de ciclos, de dimensões econômica, 
política e social interrelacionadas. A sociedade e o Estado, desde a Independência, passam por três grandes ciclos, nessa ordem: Estado e Integração Territorial (1822-1929), do Império à Primeira República, Nação e Desenvolvimento (1930-1977), aberto pela Revolução de 1930, e Democracia e Justiça Social (1977 até hoje), ou seja, desde a transição política que dá termo ao regime militar de 1964. Os ciclos abrangem diferentes pactos políticos, seja na comparação entre eles, ou, no caso dos dois últimos, na sua mutável dinâmica interna conjuntural e estrutural. Há um pacto político no primeiro ciclo, dois no segundo e três no terceiro. Estado e regime mudam.

Apoiado na melhor tradição da sociologia política e da economia política, o olhar do autor sobre o Estado é inseparável das classes, forças sociais e das coalizões de classe. Elas são alguns dos principais determinantes explicativos do poder e das ações do Estado, ou seja, do caráter mais profundo das políticas públicas, e das mudanças institucionais no poder público.

Bresser-Pereira destaca características marcantes da formação da nação brasileira, abrangendo o passado, o presente e os dilemas do vir-a-ser do desenvolvimento. Como analisado acima, o autor elabora suas ideias na trilha de diversas tradições do pensamento social brasileiro, sendo otimista sem ser ufanista. Embora esteja muito longe de qualquer apologia do status quo, aponta os aspectos positivos da formação social brasileira, como a integração territorial, a revolução nacional e industrial, e, desde a década de 1980, a emergência da sociedade civil, a conquista da democracia e das políticas públicas de bem estar social. Mas não descuida de considerar que, entre outras limitações, as transformações sociais, econômicas e políticas abertas a partir de 2003 ainda não lograram consolidar um efetivo pacto nacional-popular que seja a base sociopolítica do Estado desenvolvimentista do século XXI, tido como o agente político central do desenvolvimento.

Bresser-Pereira diferencia o liberalismo econômico - que, limitando o Estado à condição de vigia noturno, nega-lhe a condição de líder institucional do direcionamento nacionalista e desenvolvimentista da nação - do liberalismo político, que garante as liberdades individuais e os direitos civis e cujo alcance efetivo depende de o país desenvolver o mercado e dar asas à sociedade civil e às forças e relações de produção nacionais. O liberalismo econômico implica na dependência, na integração subordinada ao sistema internacional, ao passo que o desenvolvimentismo é o único caminho de desenvolvimento capitalista simultaneamente integrado, competitivo e nacionalista.

O autor insiste que é possível ao Brasil voltar a crescer, como ocorreu durante o nacional-desenvolvimentismo, desde que adote uma estratégia nacional de desenvolvimento adequada à sua condição de país capitalista de renda média, democrático, com uma sociedade civil viva e forte. O objetivo maior é o incremento das relações capitalistas de produção, a industrialização, ou sofisticação produtiva, a transferência de mão de obra de setores com menor valor adicionado para setores com maior con- 
teúdo tecnológico, o crescimento da renda, mas tudo isso com base na democracia, na percepção de que a equidade social não se alcança apenas pelo mercado e na preocupação com o meio ambiente sustentável. No longo prazo, essa estratégia deve proporcionar ganhos salariais reais e elevar a qualidade de vida de todos. Defende o programa político social-democrata, balizado nas heranças liberal (direitos civis), democrática (participação popular) e socialista (proteção social e econômica universal).

Um desafio central da estratégia de desenvolvimento é a capacitação da produção industrial nacional para concorrer com os interesses estrangeiros dentro e fora das fronteiras do país. Para tanto, é apresentado um sistema teórico e um programa normativo de desenvolvimento distinto do desenvolvimentismo clássico de Celso Furtado e Raúl Prebisch. É o Novo-Desenvolvimentismo, definido como:

a estratégia de desenvolvimento para países de renda-média, no quadro competitivo da globalização, que tem como base teórica a macroeconomia desenvolvimentista ou macroeconomia estruturalista do desenvolvimento. (p. 28)

São considerados fundamentais três princípios adotados por países bem-sucedidos na realização do catching-up, especialmente China, Coreia do Sul e Taiwan:

1) atribuir papel estratégico ao Estado; 2) demonstrar responsabilidade fiscal e 3) garantir a responsabilidade cambial através da manutenção de uma taxa de juros em nível baixo, uma taxa de câmbio competitiva e a conta-corrente equilibrada ou superavitária. (p. 390)

A preocupação com a adequação dos preços macroeconômicos, sobretudo os juros e o câmbio, aos desígnios do desenvolvimento é central em Bresser-Pereira. A elite dos intelectuais economistas brasileiros é cônscia do destaque que o ex-ministro da Fazenda no governo Sarney dá à taxa de câmbio, preço fundamental para a estratégia novo-desenvolvimentista. A política cambial desenvolvimentista deve neutralizar a doença holandesa, tendência estrutural de sobre-apreciação cíclica da taxa de câmbio ocorrente em contextos produtivos e comerciais de intensa produção e exportação de commodities, e determinada pela diferença entre a taxa de câmbio de equilíbrio corrente, vinculada à conta corrente do país, e a taxa de equilíbrio industrial, necessária para a competitividade de empresas nacionais exportadoras de bens tecnologicamente sofisticados. A não neutralização da doença holandesa desde a abertura comercial de 1900-1991 é, para Bresser-Pereira, o principal fato histórico novo que explica o baixo crescimento do Brasil depois da estabilização de preços lograda pelo Plano Real. 
Porém, como a obra toma partido, abre-se à polêmica, o que não poderia ser diferente, dada a complexidade da concertação desenvolvimentista. Ao defender o câmbio competitivo, diz:

Para que essa depreciação permanente da taxa de câmbio ocorra será necessário [...] que os trabalhadores aceitem a momentânea redução de seus salários reais, que os exportadores de commodities (que terão que pagar um imposto de exportação) compreendam que serão compensados pela depreciação que o imposto causará, e que a sociedade aceite o aumento provisório da inflação. (p. 404)

Ademais, fazendo uma referência crítica aos antigos desenvolvimentistas, Bresser-Pereira afirma que é fundamental manter a inflação controlada, mas não com o olhar exagerado dos monetaristas, e o saldo em conta-corrente, positivo. Em que medida isso tudo é politicamente viável de se alcançar?

Um tema fundamental do livro é a revolução capitalista, que "acontece para cada povo quando esse povo se torna uma nação, cria um Estado soberano, domina um território, e realiza sua revolução industrial” (p. 10). O Estado, principal instituição política e "instrumento por excelência da ação coletiva" (p. 369) de uma nação, tem papel estratégico na revolução capitalista. O capitalismo, grosso modo, apresenta dois grandes modelos econômicos, o desenvolvimentismo e o liberalismo. O modelo inicial da revolução capitalista é desenvolvimentista. Essa revolução depende de uma estratégia nacional de desenvolvimento, definida como "um conjunto de leis, políticas públicas, objetivos, entendimentos informais, no quadro de um acordo nacional, que criam oportunidades de investimento lucrativo para as empresas" (p. 49).

A revolução capitalista brasileira ocorreu ao longo do ciclo Nação e Desenvolvimento, gerando dois frutos principais, o Estado nacional e a industrialização.

A explicação de Bresser-Pereira para a formação nacional brasileira passa pela elucidação da oposição entre as classes produtoras e dinâmicas - lideradas pela burguesia industrial nacional, mas comportando, também, técnicos, burocratas e intelectuais progressistas, e, em alguns casos, os trabalhadores - e as classes rentistas e parasitárias - dos estratos de renda alta e média, que vivem da especulação sobre ativos financeiros, propriedades rurais e aluguéis. $\mathrm{O}$ autor reconhece, entretanto, que as elites brasileiras, em particular os empresários industriais, são ambíguas ou contraditórias, nacional-dependentes. Em referência à classe burguesa existente no Brasil, ora ela se portaria como legítima burguesia nacional, ora como burguesia dependente.

O autor apreende, em uma chave distinta do liberalismo econômico, o importante papel do mercado e do capital privado na atividade econômica, sendo esta regulada pelo Estado. Como os países de renda média já são industrializados e plenamente 
capitalistas, não compete ao Estado cumprir o papel de empreendedor capitalista, mas o de garantir aos empresários privados nacionais as condições ótimas de investimentos lucrativos, sobretudo uma taxa de câmbio que os conectem competitivamente aos mercados internacionais. Tais investimentos determinarão a taxa de poupança, conforme a boa e velha concepção keynesiana.

Antes de se voltar contra o populismo político, que, mesmo quando autoritário, é entendido como uma forma de participação das massas no poder político, Bresser-Pereira volta-se contra o populismo econômico, que pode ser praticado pelos liberais e pelos desenvolvimentistas. O populismo econômico pode ser cambial ou fiscal. Ocorre populismo cambial, uma das principais preocupações do autor, quando o Estado-nação, visando a combater a inflação e dar acesso ao consumo, ou promover o crescimento por meio de poupança externa, sobrevaloriza a moeda nacional, gasta mais do que arrecada e acumula déficit nas transações correntes, ao mesmo tempo em que prejudica a competitividade da industrial nacional. Essa política tem se revelado contraproducente em matéria de crescimento. Já o populismo fiscal tem a ver com os déficit públicos não sustentáveis, tendo ocorrido em governos de diferentes orientações ideológicas.

Enfim, essa resenha mencionou brevemente apenas alguns pontos de uma obra plena de conteúdos. A construção política do Brasil é um livro apto a ocupar um lugar de destaque nas interpretações contemporâneas do país. Acima de tudo, trata-se de uma obra nacionalista, mas de um nacionalismo econômico, desenvolvimentista, e não o xenófobo e totalitário, como o fascista. Trata-se de um nacionalismo democrático do século XXI, que resgata o papel estratégico da Nação e do Estado para elevar o conjunto da população ao máximo de dignidade proporcionada por uma economia de mercado plenamente desenvolvida e integrada às cadeias globais de comércio, estimulando a riqueza nacional e a produção, metas coletivas de um povo que se reconhece como tal.

O esforço dos nacionalistas brasileiros, como Oliveira Vianna, Celso Furtado e os intelectuais do ISEB, é atualizado para as demandas de um novo século, quando a pluralidade das forças sociais, em contexto de regime democrático, demanda do Estado não apenas a legitimidade proveniente do desenvolvimento econômico, mas tudo o que o processo civilizatório logrou tornar ideário dos povos modernos contemporâneos, "segurança, liberdade, bem-estar, razoável igualdade e a proteção do meio ambiente" (p. 407). O conjunto de reflexões com o qual Bresser-Pereira brinda o leitor com A construção política do Brasil de fato não se constitui como teoria, mas sim como pensamento, não como sistematização abstrata, mas como reflexão dos problemas concretos brasileiros sob uma ótica interdisciplinar, que busca equacionar o desenvolvimento com a democracia. A construção política do Brasil constitui, em um país cujo desenvolvimento ainda é uma promessa, um manifesto político pela transformação, pelo desenvolvimento da Nação. 


\section{REFERÊNCIAS}

FAORO, R. Os donos do poder. 2 ed. Porto Alegre: Ed. Globo; São Paulo: Edusp, 1975.

HOLANDA, S. B. Raízes do Brasil. 17 ed. Rio de Janeiro: José Olympio, 1984.

LYNCH, C. Por que pensamento e não teoria? A imaginação político social brasileira e o fantasma da condição periférica (1880-1970). DADOS, Rio de Janeiro, v. 56, n. 4, p. 727-767, 2013. Disponível em: <www.scielo.br/pdf/dados/v56n4/v56n4a01.pdf >. Acesso em: 8 jul. 2015. 